\title{
Exploration of the Role-Playing Model in Primary School Class Activities Under the Background of "Class Activity Month"
}

\author{
Siliang $\mathbf{Y u}^{*}$ \\ Faculty of Education, Mahasarakham University, Mahasarakham 44150, Thailand \\ *Corresponding author: Siliang Yu, 553215751@qq.com
}

\begin{abstract}
Education in the new era advocates taking students as the main body and improving students' core literacy on this basis. Subjectivity has also become one of the keys to quality education. Primary school is not only the initial stage of life, but also the key period to develop students' subjectivity. At present, there are many problems in class activities, such as the weak concept of taking students as the main body, the lack of subject consciousness among students, the flawed construction system of class activities, the unreasonable evaluation system of class activities, and so on. By establishing the role-playing model under the background of "class activity month," students can play different roles in class activities and participate in various links, such as theme selection, scheme design, organization, implementation, summary, and evaluation of class activities. Through this process, it does not only improve the quality of class activities, but also cultivate students' subject consciousness and ability in a certain subject, thus highlighting their subject status in class activities.
\end{abstract}

Keywords: Class activity month; Role-playing model; Class activity in primary school

Publication date: November 2021; Online publication: November 30, 2021

\section{1. "Class activity month"}

"Class activity month" is a series of class activities comprising of four to five activities. "Class activity month" is based on the suggestion of carrying out multiple activities to meet the needs of more students in the investigation of the current situation of class activities. "Class activity month" can provide more students with opportunities to participate in class activities, meet the needs of more students, and create a good environment for the implementation of the role-playing model.

\section{Role-playing model}

Linda L. Morse, an American scholar, has established the "Whole School, Whole Community, and Whole Child" model, referred to as WSCC. This research aims to create meaningful roles for students, encourage them to become allies, decision makers, planners, and consumers, as well as cultivate talents who can meet the current challenges and possible future. By allowing students to participate, giving them rights, and recognizing them as capable and valuable partners in the activities, the subjectivity of students can be enhanced ${ }^{[1]}$. Based on this, the role-playing model is proposed. The "role-paying" model refers to class activities that involve role-playing. It allows the students to play four roles, which include activists, planners, organizers, and assessors, in the four links of class activities: activity content, activity design, activity implementation, and activity evaluation, thus endowing them with power to promote their subjectivity in role-playing. Students play an active role in the selection of class activities; that is, students can put forward valuable suggestions for the determination of class activities according to their preferences and experience. 
In activity design and organization, students play the roles of planners and organizers, where they are given the opportunity to participate in the planning of activities according to their own preferences and form planning groups that would be responsible for the planning and implementation of the corresponding activities. In activity evaluation, students play the role of valuators; they should practice self-evaluation as planners and organizers as well as evaluate the activities they participate in as participants. The purpose of evaluation is to help students establish their own subject consciousness and summarize the experience as well as shortcomings of the activities, so as to provide reference for the development of activities in the future.

\section{Value implication of the role-playing model}

The value of the role-playing model under the background of "class activity month" is mainly reflected in a few aspects.

(1) The model effectively improves students' participation in class activities. The content of the activity is derived from the opinions of the students, which is in line with their interests. In that case, the students' union would actively participate in these activities. At the same time, multi-themed class activities can meet the needs of more students and provide opportunities for students to participate in class activities.

(2) The model breaks the role of students being only as "participants" in class activities. Students can participate in all links of class activities while having different roles, so that the activities can be more widely participated and not just as a stage for students to perform.

(3) It changes teachers' ideas, strengthen students' subject consciousness, and establish students' status as masters. Having loss their "voice" for a long time ensues an unwillingness to "speak" among students ${ }^{[2]}$. Class activities are usually arranged by schools and head teachers. However, the roleplaying model urges teachers to change the "teacher-centered" concept in class activities. It enlightens teachers in their understanding of the purpose in carrying out the activities, which is to encourage students to speak more and participate. For students, it provides opportunities to speak while bring respected by teachers. This helps students to realize the concept of "my suggestions may not be accepted, but as a member of the class, I have the right to put forward my own opinions and ideas in the development of class activities."

(4) It cultivates skills and promotes achievements. The role-playing model under the background of "class activity month" provides various opportunities. Students can participate in all links of the activity according to their interests, especially the planning and organization link, which is beneficial to the cultivation of students' sense of cooperation, innovation, and achievement.

(5) It helps build a democratic and harmonious class as well as promote the efficient and high-quality development of class activities. The role-playing model is based on the premise of mutual respect and equal relationship between teachers and students as well as among students themselves. This is conducive to the establishment of a democratic and harmonious class. At the same time, giving full play to students' subjectivity cannot be achieved overnight, but requires continuous consolidation and strengthening. The role-playing model can continuously strengthen students' subjective consciousness, promote their continuous exertion of subjectivity in class activities, and strengthen their ability. This in turn would promote the development of more efficient and high-quality class activities. 


\section{Implementation strategy of the role-playing model}

\subsection{Selecting themes based on students' needs}

Class activities are important in cultivating students' sense of ownership. Through democratic participation and voting in the selection of themes, students' subject consciousness can be enhanced. Students should be encouraged to express their thoughts on the themes for the activities by raising their hands. Their needs should be assumed as the selection option of the themes. Another way is for each student to write their favorite activities on a note, making note of their opinions and sorting out the theme that excite students. However, the selection of themes should not only consider students' interests and needs, but also warrant teachers to screen the themes proposed by students. Whether the theme is conducive to students' development and whether the activities are operable are important factors that teachers should consider. Teachers should not only respect and bring into full play the subjectivity of students, but also their own dominance, so that class activities can better promote students' subjectivity.

\subsection{Mobilizing students to participate in activity design}

The design of class activities is an important link to reflect students' subjectivity, initiative, and innovation. The participation of students in the design of class activities allows the class activities to reflect their will and increase their participation. At the same time, students' participation in activity design promotes students to become the masters of class activities. Only when an individual becomes independent, he or she will then develop subjectivity. On the contrary, when an individual is bound, he or she becomes a tool and loses subjectivity ${ }^{[3]}$. Therefore, it is necessary to break the traditional mode in activity design, where teachers design class activities and students only participate in them. Only when students become the masters of class activities, then their subjectivity can be effectively realized. Students should be given the opportunity to play the role of planners in designing class activities through planning groups. The purpose is to enhance students' subjectivity, cultivate their teamwork, give play to collective wisdom, and perfect the activity design. However, due to the limitation of age, the activity design may lack in many aspects. Teachers should actively guide and help students to design class activities. For example, in planning for class activities, the planning group reply mode can be adopted; that is, the planning group reports the design scheme to the whole class and accepts questions from the head teacher as well as students, thus forcing the students to think about the existing problems and give full play to their initiative.

\subsection{Relying on students to organize activities}

Students' subjective initiative can be realized through planning, organization, management, and regulation. It makes the practical activities of a subject more purposeful, directional, and procedural. Relying on the implementation of activities by students provides students a clearer picture about the purpose and direction of the activities; this is conducive to the realization of the function of class activities. At the same time, in the process of organizing activities, the program designed would inevitably have some contradictions in the process of practice, creating conditions for students to give full play to their initiative and creativity. Teachers should guide students to manage and regulate activities, so as to solve the problems encountered in the process. It promotes the exertion of students' initiative and the improvement of their problem-solving skills. The planning group is not only responsible for the activity design, but also the organization and implementation of the activity. With the transformation of the role from a planner to an organizer, the skills required by students to play those roles can be improved. Through activity implementation, students' subject consciousness would be further improved. By facing the issues of how to meet the preset requirements and the problems arising in the process as well as how to solve them would greatly mobilize students to give full play to their initiative and creativity. On the one hand, the implementation of class 
activities organized by students can promote the exertion of their subjectivity; on the other hand, it helps students to clearly understand the development process of class activities and form valuable experience for the development of class activities in the future.

\subsection{Establishing an evaluation model with diversified subjects}

At present, the evaluation subject of class activities is single, and there is a lack of evaluation after activities. Evaluation is very important for the exertion of students' subjective function and the optimization of class activities in the future. Therefore, it is necessary to have diversified evaluation subjects, change the previous single evaluation of students by head teachers, allow the evaluation to promote the reflection of teachers and students, as well as promote the common growth of teachers and students. A multi-agent evaluation system based on the self-evaluation of the planning group, the evaluation of the students participating in the activity, and the summary evaluation of the head teacher can be formed. Planning groups can summarize the problems and share the experience of the activities with the whole class; students participating in the activities can share their feelings and provide suggestions on the development of activities; head teachers can provide constructive feedbacks on the activities to the planning groups. Through this multi-agent evaluation system, it is conducive to cultivating students' ability to reflect and summarize as well as further enhancing students' own subject consciousness.

In short, in previous evaluations, students were not the subject of evaluation but the object being evaluated. Establishing an evaluation model with multiple subjects can enable students to see their own advantages and shortcomings from the evaluation, so as to enhance their potential, mobilize their enthusiasm and initiative to participate in class activities, as well as to give full play to their subjectivity.

\section{Conclusion}

Establishing a role-playing model under the background of "class activity month" is beneficial. Students play different roles in the process of organizing class activities by participating in various links, such as theme selection, scheme design, organization, implementation, summary, and evaluation. This process improves the quality of class activities; at the same time, it also cultivates students' subject consciousness and ability of a certain subject, so as to highlight their status in class activities.

\section{Disclosure statement}

The author declares that there is no conflict of interest.

\section{References}

[1] Morse LL, 2015, Placing Students at the Center: The Whole School, Whole Community, Whole Child Model. Journal of School Health, : 785.

[2] Li W, 2009, Gradually Improve Class Activities and Improve the Realm of Class Management. Research on Educational Science, (11): 48-51.

[3] Zhang T, 2001, Subjectivity Education, Educational Science Press, Beijing, 46. 